\title{
Desacordar el acuerdo: la disputa pública entre parlamentarios por la implementación del tratado de paz en Colombia
}

\section{Giohanny Olave ${ }^{1}$}

Recibido: 09/03/2018

Aprobado por pares: 24/04/2018
Enviado a pares: $14 / 03 / 2018$

Aceptado: 30/04/2018

DOI: 10.5294/pacla.2019.22.2.6

Para citar este artículo / to reference this article / para citar este artigo Olave, G. (2019). Desacordar el acuerdo: la disputa pública entre parlamentarios por la implementación del tratado de paz en Colombia. Palabra Clave, 22(2), e2226.

DOI: 10.5294/pacla.2019.22.2.6

\section{Resumen}

Con la firma del tratado de paz entre el Estado colombiano y la Fuerzas Armadas Revolucionarias de Colombia (FARC) en 2016, los partidos políticos y sus sectores sociales representados radicalizaron posiciones favorables y desfavorables en torno a la implementación de los acuerdos. En este artículo, el objetivo es analizar una de esas disputas, retransmitida en vivo desde un programa radial de debates y adelantada por dos diputados de partidos políticos enfrentados. El método de análisis es interpretativo e inductivo, con foco en los ataques y en las defensas verbales desplegadas. En los resultados, se hace énfasis en el problema de la representación democrática y en las tácticas de combate para orientar la opinión pública. En las conclusiones, el recorrido analítico destaca la centralidad de los combates verbales mediatizados por la radio de opinión en streaming y la estrechez del esquema de la victoria y la derrota en las discusiones públicas. El aporte del artículo es la interpretación de un momento coyuntural de discordias públicas, en el momento histórico de la transición hacia la paz con

1 orcid.org/0000-0001-6794-6472. Universidad Industrial de Santander, Colombia. giolavar@uis.edu.co 
las guerrillas colombianas. El análisis permite ver cómo las fuerzas políticas contrapuestas luchan a favor y en contra de la implementación del tratado firmado. Para el sector de oposición, se trata de "desacordar el acuerdo" desde el reclamo de haberlo derrotado con la victoria del No en el plebiscito refrendatorio. Ese reclamo de la victoria no concedida bloquea la implementación de lo acordado y arroja a la lucha a los contradictores en las arenas públicas.

\section{Palabras clave (fuente: tesauro de la Unesco)}

Debate; paz; estrategias; estrategia de desarrollo; transmisión en vivo; radiodifusión; flujo de noticias; tratado de paz; plebiscito; streaming; radio; Colombia; FARC; política; comunicación política. 


\section{Undoing the Agreement: The Public Dispute between Parliamentarians over the Implementation of the Peace Deal in Colombia}

\section{Abstract}

Upon signing the peace deal between the Colombian state and the Revolutionary Armed Forces of Colombia (FARC, from its initials in Spanish) in 2016, political parties and the social sectors that they represented, radicalized favorable and unfavorable positions on the implementation of the agreements. This article aims to analyze one of these disputes involving two deputies of opposing political parties that was broadcast live on a debate radio show. The analysis method is interpretive and inductive, focused on the verbal attacks and defenses displayed. Results emphasize the problem of democratic representation and combat tactics to guide public opinion. In conclusion, the analytical walk-through highlights the centrality of verbal combats mediated by streaming opinion radio and the narrowness of the victory-defeat scheme in public discussions. The article contributes to interpreting the current public discord, at the historical time of transition towards peace with the Colombian guerrillas. The analysis shows how opposing political forces fight for and against the implementation of the signed deal. For the opposition sector, it is about "undoing the agreement" based on the "No" victory in the peace referendum. This claim of denied victory blocks the implementation of the deal and causes contradictors to fight in public arenas.

\section{Keywords (source: Unesco Thesaurus)}

Discussion; peace; development strategies; live broadcast; broadcast; news flow; peace treaties; plebiscite; streaming; radio; Colombia; FARC; politics; political communication. 


\section{Desacordar 0 acordo: a disputa pública entre parlamentares pela implementação do tratado de paz na Colômbia}

\section{Resumo}

Com a assinatura do tratado de paz entre o Estado colombiano e as Forças Armadas Revolucionárias da Colômbia (FARC) em 2016, os partidos políticos e seus setores sociais representados radicalizaram posições favoráveis e desfavoráveis em torno da implementação dos acordos. Neste artigo, o objetivo é analisar uma dessas disputas, transmitida ao vivo por um programa de debates de uma rádio e promovida por dois deputados de partidos políticos opostos. $\mathrm{O}$ método de análise é interpretativo e indutivo, com foco nos ataques e nas defesas verbais implantadas. Nos resultados, faz-se ênfase no problema da representação democrática e nas táticas de combate para orientar a opinião pública. Nas conclusões, o percurso analítico destaca a centralidade dos combates verbais transmitidos ao vivo pela rádio de opinião e a proximidade do esquema de vitória e derrota nas discussões públicas. A contribuição do artigo é a interpretação de um momento conjuntural de discórdia pública, no momento histórico de transição para a paz com as guerrilhas colombianas. A análise nos permite ver como as forças políticas opostas lutam a favor e contra a implementação do tratado assinado. Para o setor de oposição, trata-se de "desacordar o acordo" a partir da reivindicação de tê-lo derrotado com a vitória do "não" no referendo. Essa reivindicação da vitória não concedida bloqueia a implementação do que foi acordado e coloca os contraditores em arenas públicas de disputa.

\section{Palavras-chave (Fonte: tesauro da Unesco)}

Debate; paz; estratégias; estratégia de desenvolvimento; transmissão ao vivo; radiodifusão; fluxo de notícias; tratado de paz; plebiscito; streaming; rádio; Colômbia; FARC; política; comunicação política. 


\section{Introducción}

Más de medio siglo de confrontación armada entre las Fuerzas Armadas Revolucionarias de Colombia (FARC) y los gobiernos colombianos finalizó en 2016, con la firma de un acuerdo de paz después de cuatro años de difíciles negociaciones. El tratado establece un conjunto de compromisos bilaterales en torno al desarrollo agrario, la participación política, el fin del levantamiento en armas, el problema de las drogas ilícitas, la reparación de las víctimas y el mecanismo de refrendación nacional de los acuerdos. Estos compromisos pretenden desactivar las causas sociales de un conflicto armado interno, cuyo saldo se estima en una cifra superior a los ocho millones de víctimas (Red Nacional de Información [RNI], 2017), principalmente de los sectores más vulnerables de la sociedad civil.

Las partes acordaron que el mecanismo de refrendación de los acuerdos sería la consulta popular a través de un plebiscito. El 2 de octubre de 2016, el 37,43 \% de los colombianos participaron respondiendo Sí o No a la pregunta " ¿Apoya el acuerdo final para la terminación del conflicto y construcción de una paz estable y duradera?” El 50,21 \% de los votantes rechazaron el acuerdo, mientras que el 49,78 \% respondieron positivamente (Registraduría Nacional del Estado Civil, 2016). Frente a este resultado adverso, las partes propusieron una segunda versión del acuerdo, que incluiría los reparos hechos por los sectores que votaron No en el plebiscito. Este acuerdo definitivo fue refrendado por el Congreso de la República, el 30 de noviembre de 2016; ratificación que permitiría iniciar la implementación de los compromisos firmados por los representantes de las FARC y del Estado colombiano.

A lo largo de todo este proceso de finalización del conflicto armado interno, se fue consolidando un sector de oposición política al acuerdo de paz, que lideró en diferentes momentos el control a los actores de la negociación y las críticas a los compromisos adquiridos por el Estado. Gran parte de esta fuerza de oposición se concentró en el partido político denominado Centro Democrático, dirigido por el expresidente Álvaro Uribe Vélez (2002-2010) y con parlamentarios activos en el Congreso de la República. 
En este trabajo, propongo analizar la disputa pública sostenida por una representante del Centro Democrático con un representante de un partido contradictor, a propósito de dos posiciones opuestas sobre la implementación del acuerdo de paz referido.

\section{Soporte teórico}

Inscribo este trabajo en el campo de los estudios emergentes de la argumentación, en que algunos autores abordan las disputas públicas como "discursos erísticos" (Gauthier, 2012; Jackiewicz, 2017; Olave, 2018; Reygadas, 2015 , p. 457). La argumentación erística cumple cuatro funciones que fundamentarían su inclusión en este campo de estudios: a) una función epifánica o de catarsis de un conflicto, b) una función de autodefensa contra los falsos razonamientos y sus trucos (heredada del trabajo clásico de Schopenhauer [1830/2011] y de Kotarbinski [1963]), c) una función crítica refutativa o de aprendizaje de lo previamente ignorado y de construcción de acuerdos más hondos y d) una función política que aspira a revertir una relación injusta, de dominación y abuso de poder (Reygadas, 2015, pp. 457-523). El término erística es rescatado, principalmente, de la herencia aristotélica (Aristóteles, 1991) con el sentido de contienda o lucha verbal que desborda las regulaciones de la dialéctica y los ideales de la discusión racional, pero también proviene de una larga tradición desde la epopeya y el mundo mítico griego (Olave, 2018).

Desde una perspectiva retórica contemporánea, uno de los aspectos más destacados de la metáfora de la lucha física en las relaciones erísticas verbales es el papel del auditorio. En efecto, Angenot (2013, p. 335) apunta que este tipo de disputa "es un espectáculo que supone un público cruel, que no es exigente sobre los medios sino que le interesan los golpes y ver que alguno de los contendientes - el que sea - caiga a tierra”. En este sentido, el destinatario de los combatientes no es el contradictor, sino el público que asiste a la lucha.

En esta misma perspectiva, el denominado análisis del discurso polémico (Montero, 2016) viene conformando un área creciente de estudio inscrita o ligada directamente con teorías francesas de la argumentación. 
Estas visiones avanzan en dirección a una retórica centrada en la funcionalidad social del disenso y de la interincomprensión entre personas o grupos (Maingueneau, 1983), pero no como formas dogmáticas de la discusión ni como desviaciones (sorderas) del diálogo (Angenot, 2008). En esta línea, algunos autores como Amossy $(2014,2017)$, Kock $(2007,2009)$ y Plantin $(2003,2011,2012)$ se proponen abordar la polémica como fenómenos comunicativos en que es necesario desplazar el problema del "convencer al otro" por el de "coexistir en la diferencia".

Estas perspectivas discursivas tienen soporte en el modelo del "pluralismo agonista”, proveniente de la filosofía política en clave posestructuralista (Laclau y Mouffe, 1987; Marchart, 2007). Su aporte teórico principal es un intento de proporcionar instituciones políticas que, sin erradicar el conflicto, sean capaces de garantizar la coexistencia en la diferencia radical. Mouffe (2000) propone reconocer el vínculo indisociable entre antagonismo y agonismo, aceptar el conflicto como esencia de lo político y radicalizar las instituciones democráticas liberales para que garanticen la pluralidad y organicen la emergencia de los múltiples disensos. Así, este modelo de democracia aspiraría a que los contradictores políticos no se vieran entre sí como enemigos por exterminar, sino como adversarios en permanente desacuerdo.

Esta perspectiva desplaza la aspiración al consenso e inclusive a una ética erística, por la apertura de espacios que transmuten la violencia física en catarsis verbal y en que el disenso pueda explotar sin dañar físicamente al otro. El centro de las cuestiones sigue siendo vivir juntos que, desde esta perspectiva del discurso, se canaliza propiamente en el uso de la lengua. Como bien lo señala Montero (2016, pp. 10-12), la afirmación de la alteridad constitutiva del lenguaje abonó desde muy temprano el terreno para los estudios de la polémica en él. Esa alteridad esencial del lenguaje devino hipótesis de trabajo sobre el carácter constitutivo de lo polémico en las diferentes reflexiones aparecidas desde la década de los ochenta; en ese sentido, la analogía entre la polémica y lo polémico con la cuestión de la política y lo político es perfectamente posible (Marchart, 2007; Mouffe, 2000; Rosanvallon, 2002): "En la medida en que el criterio asociativo/disociativo de lo político es un criterio fundante, lo polémico 
le es co-sustancial. En suma, todo lo político es polémico y, recíprocamente, todo lo polémico es político" (Montero, 2016, p. 14).

La especificidad de la erística en los estudios del discurso polémico radica en poner el foco en los modos a través de los cuales se hace permanecer la diferencia, se prolonga el conflicto y se profundiza en las acciones de fuerza hasta el borde que limita con el abismo de las agresiones físicas.

El escenario de la disputa analizada se ubica en el fenómeno de la convergencia multimedia de los medios de comunicación tradicionales y particularmente de la radio (Cebrián, 2001; Soengas, 2013), lo que ha permitido ampliar su formato hacia lo audiovisual. Esa convergencia también la ha conminado a adaptarse a las posibilidades de la multimodalidad (imagen, sonido y texto simultáneos) y la hipertextualidad (enlazamiento y acceso directo a otros textos) para la interactividad con las audiencias, las que cuentan con herramientas múltiples (llamada telefónica, videollamada, botones de valoración, generación de trending topics, interacción en redes sociales, etc.) para mostrar públicamente sus reacciones en tiempo real frente al contenido que el programa les ofrece.

En este marco, el programa de debates de W Radio ofrece retransmisión audiovisual en redes sociales, a través de Facebook Live, que incorpora la emisión en directo y las reacciones de los usuarios de esa red social digital. Este sistema ha impactado la producción, circulación y recepción de los contenidos periodísticos, así como la composición de sus géneros tradicionales (Pulido y Sánchez, 2017, pp. 85-102), especialmente por la incorporación activa de las audiencias y la ampliación espaciotemporal de la difusión de los contenidos. Esta característica abona a la mayor difusión del programa radial, al romper la espaciotemporalidad inmediata de la emisión; hasta la fecha actual, el video del debate analizado cuenta con 7576 comentarios en Facebook y 1736 en YouTube, lo cual indica cuantitativamente la atención obtenida por parte de los usuarios de estas redes sociales.

El diseño del programa sigue el perfil general del debate político entre dos participantes, convocados por la emisora de acuerdo con sus filiacio- 
nes partidarias e ideológicas contrapuestas, pero con condiciones similares en cuanto a su rol político institucional (parlamentarios del Congreso de la República) y su visibilidad pública (figuras reconocidas en el ámbito por su trayectoria y militancia). Esa selección refuerza la expectativa genérico-discursiva de la contienda y el despliegue de puntos de vista opuestos; precisamente, en esa controversia esperada y posiblemente crispada, se deposita la esperanza de captación de la tribuna de las redes sociales y el consumo del producto radial en streaming.

El programa radial tuvo la restricción del tiempo de transmisión en vivo, dentro de la parrilla diaria de la emisora, pero no se impusieron explícitamente tiempos de intervención a los participantes. La moderadora principal, una periodista reconocida en el medio de opinión, propuso la siguiente pregunta para estructurar la discusión: "Dijo el expresidente Álvaro Uribe que, si el uribismo gana las elecciones presidenciales de 2018, el nuevo presidente cambiaría los acuerdos con las FARC. ¿Es posible?” (0:10-0:30).

\section{Metodología}

Propongo abordar la disputa pública en cuestión desde una perspectiva interpretativa interdisciplinar como una práctica analítica que relaciona materiales textuales auténticos con saberes referidos al campo en que han sido producidos (Arnoux, 2006). En el mismo sentido, sigo los "principios del análisis de las interacciones verbales" o "análisis del discurso en interacción" (Kerbrat-Orecchioni, 2007) que privilegia el uso de datos naturales, la selección pertinente de los elementos contextuales y el posicionamiento del analista como "archiinterpretante", quien opera a partir de la descripción rigurosa de las unidades semióticas (verbales, paraverbales y no verbales) que componen sincréticamente la textualidad de la interacción (KerbratOrecchioni, 2010, p. 45).

El corpus lo constituye el video de un debate radial retransmitido audiovisualmente en redes sociales el 22 de junio de 2017 y disponible en la página web de la emisora W Radio, programa Cuadrilátero de la W. La grabación se extiende durante 48:34 minutos y fue procesada a través de segmentación, transcripción y anotación, con ayuda del software ELAN 5.0. 
La transcripción fue de carácter cerrado (Jenks, 2011, pp. 12-13), focalizada en la disputa entre los actores. Se acogieron convenciones provenientes de las tres principales tradiciones en análisis de la conversación (CA, GAT y SBS, según Jenks, 2011, p. 115) (véase anexo).

Las fases analíticas del proceso se desarrollaron como sigue: primero, se distinguió el objeto principal de la discordia y su aparición, de manera intermitente, pero predominante, o largo del programa radial. Segundo, se focalizaron las interrupciones y los solapamientos como indicios de segmentos en que el diálogo cooperativo y la gestión de turnos son transgredidos, desviados o redimensionados conflictivamente. Tercero, se tradujeron las acciones verbales y paraverbales como modos del ataque y la defensa en torno a la orientación de la opinión pública. Y cuarto, se reconstruyó la producción de sentidos políticos en estos tramos de disputa y sus relaciones con el problema de vencer y ser vencido en el escenario público.

\section{Resultados}

La discordia entre los diputados tuvo como trasfondo el problema de la representación de un sector amplio del país que negaba la legitimidad política del acuerdo de paz firmado con las FARC. La crisis general de la representación democrática en las sociedades contemporáneas, leída como deterioro de la confianza en las instituciones y en su capacidad de interpretar las demandas de los ciudadanos (Rosanvallon, 2007, pp. 2138 ), conduce a la construcción de la legitimidad política como un objeto de discordia.

Se entiende aquí la legitimidad política en un orden retórico de conducción de la creencia pública, esto es, inscrita en la arena de las luchas entre representantes de intereses políticos y constitutiva de una discordia que los distancia entre sí, pero que también los aproxima para el combate. Esta introducción de la legitimidad política en el régimen de la lucha no borra su existencia por fuera de la arena, donde puede verse como sujeción y adecuación a un cierto orden normativo o de valores (Weber, 1922/1979, p. 26), como reconocimiento de la racionalidad argumentativa y moral de ese orden (Habermas, 1981, p. 249), como obedecimiento a un poder y una asi- 
metría debidamente autojustificados (Ferrero, 1998, p. 181) o como formas contingentes de aprehensión del imperativo democrático de expresión de la generalidad social (Rosanvallon, 2009, p. 27). No obstante, bajo los imperativos del combate verbal, la legitimidad política pierde su estatus óntico y se convierte en un objeto que representa el premio para el contendiente más fuerte. Pasamos aquí, de una visión de legitimidades en disputa, en el espacio extrínseco del orden político en que coexisten diferentes fuentes de legitimación que compiten entre ellas (Zarka, 2010), a una mirada intrínseca y específica de las formas en que se disputa la posesión de lo políticamente legítimo.

El problema aproxima la legitimidad a la orientación de la opinión pública. Como lo plantea Quiroga (2013,p. 69), esta última constituye una fuente de legitimidad democrática en el escenario de lo público, signado por la presencia permanente de los medios masivos de comunicación y las redes sociales virtuales, lo que la hace, además, "una legitimidad más volátil, una especie de legitimidad intermitente" fundada sobre opiniones efímeras, que funge como juez y destinatario de las decisiones gubernamentales. En este sentido, la legitimidad democrática y la opinión pública terminan siendo codependientes: la conquista de la segunda es la condición de existencia de la primera, y en correspondencia, la opinión pública es defendida desde la legitimidad del objeto al que se adhiere:

La legitimidad democrática produce un movimiento de adhesión de los ciudadanos indisociable de una sensación de valorización de ellos mismos. Condiciona la eficacia de la acción pública y al mismo tiempo determina la manera en que perciben la cualidad democrática del país en el que viven. (Rosanvallon, 2009, p. 32)

Lo más interesante de esta relación entre opinión pública y legitimidad política es que a la primera suele invocársele como la fuente de donde proviene la fuerza que se utiliza en los escenarios de la contienda (electoral, parlamentaria, colectiva civil, sindical, etc.). Así, la denominada fuerza de opinión es empleada en la lucha que libra cada contrincante por mostrarse como el portavoz de las mayorías. 
En este terreno de la representación democrática, la lucha se libra en torno al rechazo o la aceptación de la implementación del acuerdo de paz, según se lo conciba como un producto políticamente legítimo o ilegítimo, de acuerdo con las siguientes premisas, que arriban a la pretensión de modificarlo, por un lado, o de ejecutar sus disposiciones, por el otro (tabla 1).

\section{Tabla 1. Premisas enfrentadas sobre el acuerdo de paz}

\begin{tabular}{|l|l|}
\hline \multicolumn{1}{|c|}{ Acuerdo ilegítimo } & \multicolumn{1}{c|}{ Acuerdo legítimo } \\
\hline $\begin{array}{l}\text { Fue rechazado por la ciudadanía en un plebiscito } \\
\text { refrendatorio. }\end{array}$ & $\begin{array}{l}\text { Fue rechazado por un margen mínimo de diferencia porcentual }(0,43 \%) \\
\text { y con una participación exigua }(37,43 \%) .\end{array}$ \\
\hline $\begin{array}{l}\text { No fue modificado sustancialmente durante la } \\
\text { etapa de revisión posplebiscitaria. }\end{array}$ & $\begin{array}{l}\text { En el texto final, se incluyeron noventa propuestas provenientes de los } \\
\text { sectores de oposición al acuerdo. }\end{array}$ \\
\hline $\begin{array}{l}\text { Fue aprobado por mayorías del Congreso de la } \\
\text { República, no por voto popular. }\end{array}$ & El Congreso de la República es un organismo de representación popular. \\
\hline $\begin{array}{l}\text { Les permite a los exguerrilleros participación } \\
\text { política antes de ser judicializados. }\end{array}$ & $\begin{array}{l}\text { El desarme está condicionado a la participación política de los } \\
\text { exguerrilleros, por ser un proceso de paz en vez de un sometimiento } \\
\text { o rendición. }\end{array}$ \\
\hline $\begin{array}{l}\text { Crea un régimen de justicia especial, paralelo a la } \\
\text { justicia ordinaria. }\end{array}$ & $\begin{array}{l}\text { Las negociaciones para acabar conflictos armados implican un } \\
\text { tratamiento jurídico especial de los crímenes cometidos, que incluye } \\
\text { tipos de amnistías y penas alternativas. }\end{array}$ \\
\hline $\begin{array}{l}\text { Constituye una política de Estado, originada en } \\
\text { un gobierno con poco apoyo popular. }\end{array}$ & $\begin{array}{l}\text { La paz es un derecho constitucional que el presidente de la república está } \\
\text { en el deber de garantizar. }\end{array}$ \\
\hline
\end{tabular}

Fuente: elaboración propia.

En torno a estos datos, de lado y lado, se construyen argumentos y contraargumentos en diferentes momentos de la discusión transmitida. No es del interés de este trabajo describir ni evaluar el contenido de esos razonamientos argumentativos, sino reconstruir los modos de la disputa que aparecen en ellos y que llegan a desplazar la argumentación formal en algunos tramos. Sostengo que es en esas interacciones en que las reglas del debate ceden a los imperativos del combate $y$, por tanto, las acciones verbales y no verbales adquieren la forma de ataques y defensas con el propósito de ganar la razón, esto es, obtener o retener el objeto de la discordia. En este caso, la forma de ese trofeo es la legitimidad o ilegitimidad del acuerdo de paz.

La lucha por ese trofeo se libra en el frente de la representación democrática, en que los diputados combaten en nombre de los sectores sociales que aseguran defender, desde su pertenencia a partidos políticos, pero 
también por fuera de esas agremiaciones, invocando la representación de la voluntad popular:

\begin{abstract}
DIPa: ... en la campaña del No/ donde ganó el no:: | se propuso precisamente / la reforma y la reformulación de esos acuerdos | Y GANAMOS | la voluntad popular ganó/ | Y de forma INCREÍBLE | el gobierno y las mayorías del Congreso | cooptadas y enmermeladas decidieron pasar una proposición | para sencillamente | hacerle conejo | a la voluntad del pueblo\}

$[\ldots]$

la voluntad | popular | desechó | los acuerdos | y se ha debido renegocia::r || porque ganó el

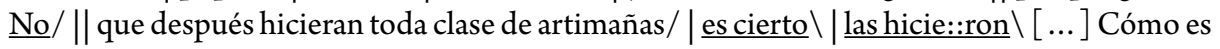
posible/ | que nosotros hayamos ganado con el No/ | diciendo que n-o p-o-d-í-a-n los criminales de lesa humanidad y de guerra participar en política $\mid$ ¡Y no lo modificaron!
\end{abstract}

$0: 35-0: 58 / 4: 59-5: 46$

El argumento de la diputada se construye sobre la base de la indignación del vencedor que denuncia que le han arrebatado su victoria. El triunfo del rechazo al acuerdo de paz, con los resultados del plebiscito refrendatorio del 2 de octubre de 2016, no se tradujo en la anulación de los compromisos adquiridos por el Estado y las FARC durante cuatro años de negociaciones. La iniciativa de refrendar por voto popular el acuerdo firmado no contó con la posibilidad de perder en las urnas, y al toparse con esta realidad, tuvo que enfrentar el triunfo de la oposición y su empoderamiento como el sector ganador, que reclamaría el derecho a modificar el acuerdo, posteriormente al proceso de paz adelantado y aun sin ser parte de la mesa de negociaciones.

La figura del vencedor aquí fue definitiva para reclamar un ejercicio de poder que había estado agazapado, traducido en oposición política y contenido por las reglas de juego del sistema presidencial de gobierno. Ganar implica reclamar el triunfo, pero, si no es claro desde antes de la competencia qué es lo que se puede ganar, la forma de la victoria la determina justamente aquel que logre ganar; en este caso, la confianza del Gobierno en el voto afirmativo para el acuerdo de paz dejó vacío el espacio de una victoria del voto negativo y, con ello, permitió que la oposición lo llenara a su conveniencia. Mientras que el Gobierno afirmaba que el escenario de la victoria del No era impensable, porque llevaría al fracaso del proceso de paz 
(según el representante gubernamental en la mesa de conversaciones ${ }^{2}$ ) e inclusive a la reanudación recrudecida de la guerra (según el propio presidente de la república), ${ }^{3}$ la oposición capitalizó ese escenario como una oportunidad de reorientación necesaria del acuerdo por una paz "sin impunidad" y que evitaría dejar "a Colombia bajo conducción de las FARC" (Uribe Vélez, 2016).

Dado que las consecuencias del triunfo del No siempre fueron políticamente impredecibles, aunque jurídicamente reguladas (Semana, 2016), la búsqueda de una posterior refrendación sin acudir al voto popular, sino a la aprobación del Congreso, le dio más armas a la oposición para afincar la idea de que el acuerdo era ilegítimo, por haber sido rechazado en las urnas. Ese mecanismo refrendatorio, que jurídicamente resultaba legal, desde el punto de vista político atizó la animadversión contra el proceso de paz y fue incorporada en la lucha como indignación frente a una acción tramposa y autoritaria del Gobierno para desconocer el triunfo de la voluntad popular. Es esa la táctica de la diputada para reclamar el triunfo no reconocido en nombre de una mayoría indignada; los énfasis paraverbales marcados en la cita (énfasis, alargamientos, deletreos y tonemas ascendentes) recaban en la cólera del sujeto engañado y en el reclamo en voz alta del premio de la victoria ya obtenida.

Inflamar y conducir el resentimiento, como emoción usualmente política e inclinada hacia la reparación de la justicia (Nussbaum, 2013, p.342), desplaza la elaboración argumentativa por la denuncia de la trampa y el reclamo de la víctima de ese engaño. Esencialmente reactivo contra una realidad que se percibe como injusticia, el resentimiento político activa una escala de valores (Danblon, 2005, p. 162), en la cual quien se presenta como

2 Así respondía Humberto de la Calle a la pregunta “¿Qué pasa si los colombianos votan que no en el plebiscito?”: “Si gana el 'no', se acabó el proceso. La historia muestra que tradicionalmente después de una ruptura con las FARC pasan diez años antes de reiniciar conversaciones. Luego, la idea del 'no' para renegociar es un tremendo error histórico. Yo creo que va a ganar el sí” (BBC Mundo).

3 "Se ha querido decir que si el plebiscito se niega vamos a poder negociar un acuerdo mejor. No, no se equivoquen. Si el plebiscito no se aprueba volvemos a la guerra, así de sencillo, no es que vamos a volver a la mesa de negociación, volvemos a la guerra. Esa es la verdad" (Santos, 2016). 
víctima queda redimido por su propia condición de doliente. Como señala Angenot (1994, p. 6), estar sujeto al poder ejercido por otro y ser impotente ante él es precisamente lo que eleva la moral del resentido y lo autoriza como superior al agresor. En este caso, será el factor de representatividad del colectivo el punto débil que aprovechará el diputado para contraatacar el embate de su rival. La táctica consistirá en poner en duda la unidad de esa representación, al confrontar dos posiciones disímiles dentro del mismo partido de oposición (Centro Democrático), frente al acuerdo de paz: reconocer su legitimidad, o por el contrario, desconocerlo y "hacerlo trizas":

\begin{tabular}{|c|l|c|l|}
\hline & DIPo: & & \\
\hline 1 & $\ldots$ hay dos tendencias en el Centro & 1 & \\
\hline 2 & Democrático los que quieren hacer & 2 & \\
\hline 3 & trizas $\mid$ y los que quieren respetar los & 3 & \\
\hline 4 & acuerdos $\mid$ y entre los que quieren & 4 & \\
\hline 5 & & 5 & DIPa: \\
\hline 6 & respetar los acuerdos y los reconoce/ & 6 & [[no- no es res:petar/ los acuerdos \\
\hline 7 & | está el expresidente [[Uribe- & 7 & los acuerdos son un adefesio/- \\
\hline 8 & pues él dice que reconocerlos $\backslash-$ & 8 & hay que re:for:mula::r/- \\
\hline 9 & esa es su posició:n $\backslash-$ & 9 & no e- no es res:petar | no es respetar- \\
\hline 10 & pero es su posició:n $\backslash-$ & 10 & aquí hay que re:diseña::r/- \\
\hline 11 & $\begin{array}{l}\text { pero de acuerdo es su posición } \backslash- \\
\text { perfecto/ pero...]] }\end{array}$ & 11 & reformular la ese:ncia/...]] \\
\hline
\end{tabular}

El tramo resaltado (6-11) corresponde al momento de tensión entre los participantes, caracterizado por las interrupciones de ambos lados (-), la lucha por sostener el turno de habla y la aparición de solapamientos problemáticos (Liddicoat, 2007, p. 87), es decir, no cooperativos. ${ }^{4}$ El contraste

4 En el área del análisis de la conversación, se han diferenciado interrupciones y solapamientos orientados hacia la cooperación (completar lo que el otro está diciendo, hacer una acotación, etc.) y otros hacia la competencia entre los hablantes (objetar, arrebatar el turno, etc.). Goldberg (1990), por ejemplo, propone distinguir, en el mismo sentido, entre power interruptions y non-power interruptions, centrándose en el nivel de despliegue de "poder" o fuerza en las interrupciones. Goldberg, sin embargo, sigue la tradición del área al prestar mayor atención a las interrupciones cooperativas y a los mecanismos de reparación de los solapamientos (Liddicoat, 2007, pp. 91-104). 
entre el predomino de los tonemas descendentes (diputado) y ascendentes (diputada) permite asociarlos con cada posición en pugna: él los utiliza para sentenciar y cerrar la discusión a través del tono asertivo y de la reiteración, mientras que la diputada eleva las entonaciones finales para negar y objetar las palabras de su contradictor, también con reiteraciones vehementes. El trabajo con los énfasis (acentos en las palabras subrayadas y alargamientos silábicos) tiene correspondencia también con esos usos prosódicos que enfrentan la objeción a la aserción.

El diputado insiste en revelar una división interna en el partido opositor en referencia al reconocimiento o no del acuerdo de paz, pero, además, enfrenta a la diputada contra la posición de su jefe de partido, el expresidente Uribe, de manera que la animadversión contra el acuerdo parezca una posición aislada o desviada (ver los énfasis subrayados) de los lineamientos centrales partidarios, lo cual debilitaría la fuerza de representación de la diputada. El ataque de su contradictor consiste en asentar la idea de que el partido opositor reconoce voluntariamente los acuerdos, a través de la explicación dicotómica de las "dos tendencias" internas: la jerarquización de la opinión del líder y el uso de las reiteraciones. La reacción a este asalto introduce un solapamiento vehemente justo en el momento en que se insiste en el "respeto" al acuerdo: en vez de respetar, es reformular y rediseñar, aclara la diputada haciendo énfasis prosódicos en los usos verbales y en la calificación de los acuerdos como "adefesio".

La lucha por la legitimidad del acuerdo, como objeto de discordia, en varios tramos de la interacción, se concentra en la capacidad de los contendientes de aislar al otro para atacarlo como individuo y no como representante de un colectivo. El respaldo de sus representados es, precisamente, lo que fortalece su decir como una opinión pública producto de un sentir masificado. En la arena política, en la amplitud de esa representatividad, radica la fuerza de acción, tanto para el ataque como para la defensa; a nivel partidario resulta fundamental, pues la fuerza de unidad se traduce en los niveles de cohesión interna, los mismos que el diputado pone en cuestión para aislar a su oponente: 


\begin{tabular}{|c|c|c|c|}
\hline & DIPa: & & DIPo: \\
\hline 1 & [[Ahora: usted me está diciendo una & 1 & \begin{tabular}{l|l|l|}
{$[$ pero } & permítame & simplemente
\end{tabular} \\
\hline 2 & pregunta $\mid$ que si se hacen trizas o no]] | & 2 & | para- para precisar/ Sí/ Sí/]] \\
\hline 3 & en el movimiento nuestro hay unos que & 3 & \\
\hline 4 & quieren- que consideran hacerlos trizas $\mid y$ & 4 & \\
\hline 5 & otros que consideran | que no/ | yo & 5 & \\
\hline 6 & personalmente le voy a decir qué pienso | & 6 & {$[[(\mathrm{p})$ Yo la invito a que se pongan } \\
\hline 7 & {$[[$ yo personalmente- $]] \mid$ no-no } & 7 & de acuerdo $\backslash \otimes]]$ \\
\hline 8 & necesariamente hay que tener de acuerdo & 8 & \\
\hline 9 & a todo el mundo | esto no es el Partido & 9 & {$[[;(p)$ no, ni el Partido Nazi/ / o- } \\
\hline 10 & Comunista/| [[Entonces simplemente | & 10 & ¿o sí es el Nazi?:)| OK | No:: y el \\
\hline 11 & el agua | corre- ¡tampoco! | pero son & 11 & Nazi hoy es...[???]\} \\
\hline 12 & similares el Comunista y el Nazi]] & 12 & \\
\hline
\end{tabular}

La segunda intervención con solapamiento del diputado (6-7) remarca el desacuerdo interno del partido opositor, ataque que se apuntala en la risa sostenida y en el sarcasmo introducido en el siguiente solapamiento (7$9)$. La diputada cede ante las provocaciones e interrumpe dos veces su intervención (6 y 9) para ripostar las burlas del diputado. En el contraataque, ella devuelve el golpe sobre la fragmentación interna del partido rechazando (6-7) el unanimismo del Partido Comunista — con el cual simpatizaría el diputado... y asimilándolo al Partido Nazi (9-10). La defensa se ha convertido velozmente en un ataque, para neutralizar el embate contra la cohesión interna del partido opositor.

La agresividad en las interpelaciones del diputado es indirecta y discreta, no solo por abrirse paso a través de interrupciones en voz baja y por usar sarcásticamente la invitación ("Yo la invito a que se pongan de acuerdo”) y la pregunta dubitativa (“¿o sí es el Nazi?”), sino, sobre todo, por la presencia de la risa, sostenida durante el intercambio (6-10) y contrastada con la molestia evidente de la diputada. La risa/sonrisa permite desactivar la seriedad o la agresividad de lo dicho por el oponente y, con ello, dominar el momento de la lucha. Sostener la sonrisa demuestra que se tiene la fuerza suficiente para rechazar la provocación del enemigo: la potencia de su ataque resulta inofensiva. 
El trabajo político de la risa y la sonrisa no termina en la expresión de emocionalidades tradicionalmente percibidas como positivas, desde la psicología social, ni en la cooperación cortés entre los participantes al construir interacciones dialogales, como suele estudiarse desde el análisis de la conversación (Ruusuvuori, 2013, p. 346). Sandré (2011) ha mostrado que la risa/sonrisa es explotada estratégicamente por los políticos en interacciones polémicas, asignándole funciones tanto consensuales como divergentes y obteniendo efectos de atenuación, amplificación y revelación. El que sonríe más se beneficia de la imagen de simpatía y cercanía con el auditorio que aquel que tiende a aparecer más adusto en la interacción polémica, lo cual es reforzado por la necesidad de seducir al público, en el caso de los debates mediatizados.

Basado en el caso concreto de la lucha entre los diputados, es posible pensar que la risa y la sonrisa contribuyen poderosamente a la construcción de una agresividad discreta, esto es, al movimiento ofensivo que evita conscientemente transgredir las formas corteses, usándolas como una envoltura o armadura que, a su vez, le permite al atacante desplegar su fuerza con menor riesgo de ser denunciado públicamente como violento. En el mismo sentido y dentro del contexto de los debates electorales entre candidatos presidenciales, Fracchiolla (2008, pp. 502-504) y Kerbrat-Orecchionni $(2016$, p. 91) han encontrado que el "ataque cortés" es un acto de lenguaje indirecto y estratégico presente de manera regular en ese tipo de escenarios, sostenido por las restricciones y coerciones de cortesía, propias del género y del perfil de los participantes. En la interacción analizada, los diputados hacen menos énfasis en el uso de fórmulas corteses para encubrir sus ataques que en la discreción o cuidado de la mesura al emprender la ofensiva; propósito dentro del cual aparece la risa/sonrisa como neutralizador de la agresión y la persistencia en las aclaraciones, en favor de las posiciones defendidas por cada participante:

\begin{tabular}{|l|l|l|}
\hline DIPo: & & \\
\hline Perdón simplemente $\mid$ & & \\
\hline entonces $\mid$ para entender $\mid$ & MOD1: & DIPa: \\
\hline ise trata de reconocer los & {$[[$ pero yo $\mid$ yo tengo una $\mid$} & {$[[$ @epero es que $\mid$ es que } \\
\hline acuerdos y $[[$ sobre el & yo tengo una opinión & ellos quieren colonizar los \\
\hline
\end{tabular}




\begin{tabular}{|c|c|c|}
\hline reconocimiento de esos & sobre el tema]] | yo creo: & triunfos y los éxitos@)\} \\
\hline acuerdos proponer & que cuando Uribe:: | yo & \\
\hline \multirow[t]{2}{*}{ modificaciones?]] } & creo que cuando Uribe & \\
\hline & dice:: | modificar los & \\
\hline \multirow[t]{2}{*}{ DIPo: [[reconocerlos $]]$} & acuerdos $\mid$ pero a la vez & DIPa: [[“vamos a seguir \\
\hline & dice:: | [ [ vamos a seguir & con el proceso" | no dijo \\
\hline DIPo: [ [y reconocer el & \begin{tabular}{l|l} 
con el proceso digámoslo \\
\end{tabular} & "reconocemos los \\
\hline acuerdo | claramente/ | el & así:: $\mid$ o $\mid$ o reconocer... lo & acuerdos"]] \\
\hline acuerdo]] & que sea...]] & \\
\hline
\end{tabular}

9:50-10:14 1

El esfuerzo del diputado por remarcar el reconocimiento del acuerdo de paz por parte de la oposición depende de su capacidad de hacer decir o hacer aceptar a los otros lo mismo que él sostiene y que resalta tanto verbal como paraverbalmente. La discusión ha llegado a un punto muerto, pues la diputada no está dispuesta a conceder ese reconocimiento y, por el contrario, sonríe para rechazar esa concesión pretendida y acusar al enemigo de querer ganar a toda costa. La evidencia de este impase lleva a la moderadora a intervenir para destrabar el bloqueo, deshacer el $\operatorname{clinch}^{5}$ y restarle importancia a la expresión disputada, en medio de las vacilaciones y el triple solapamiento de las voces. El árbitro trata de conciliar introduciendo su opinión y poniéndose como garante de la palabra autorizada del tercero invocado, el líder de la oposición. La concesión final al diputado es resistida por la diputada, con lo cual la conciliación evidentemente fracasa; ninguno de los contrincantes ha cedido.

El énfasis en los resultados del plebiscito redujo la lógica electoral en torno a la paz del país al esquema de vencedores contra vencidos: ganó el No al acuerdo, pero esa victoria no fue reconocida sino eludida por el Gobierno, de ahí que la diputada considere ilegítima su implementación.

Es la disputa por el significado de la victoria lo que estructura la discusión y lo que les permite a los diputados atacar o atrincherarse. Para la

5 En la analogía pugilística, el clinch corresponde al momento en que los púgiles no luchan, sino que se traban en un abrazo en tensión hasta que el árbitro los separa y los conmina a continuar la pelea. 
oposición, se trata de haber ganado el derecho a imponer las condiciones para un nuevo proceso de negociación con las FARC; para el defensor del acuerdo alcanzado, en cambio, la victoria del sector del No ya fue reconocida en la reformulación del texto definitivo que aprobó el Congreso de la República. Los diputados no buscan deshacer este desacuerdo, sino más bien garantizar que permanezca, ante el auditorio. No hay aquí opción de ceder. En esta medida, la interacción analizada es más lucha que diálogo y más combate que debate; se trata aquí del predominio de los trabajos de fuerza orientados a derribar (o parecer que se derriba) y no ser derribado (o simular que no se ha caído en la arena).

Estas tareas de simulación de la victoria, nucleares en la argumentación erística (Aristóteles, 1991; Olave, 2018), se explican por la relevancia del auditorio en el desarrollo de la lucha. En el siguiente tramo, por ejemplo, la discordia se orienta hacia la solidaridad con el campesinado y su victimización estratégica en cada discurso:

\begin{tabular}{|c|c|c|c|}
\hline DIPo: & & & \\
\hline 1 & ... usted no convierta el micrófono de & & \\
\hline 2 & esta emisora digamos en una especie de & & \\
\hline 3 & $\mid$ de forma de criminalizar a la gente $\backslash \mid$ & 3 & DIPa: \\
\hline 4 & esos campesinos viven en unas & 4 & [[isí::? $\|$ no| a mí no me pida que \\
\hline 5 & situaciones muy difíciles [[yo le pido el & 5 & respete a quienes reclutan niños | \\
\hline 6 & favor que los respete/ | porque-]] & 6 & como los miembros de la XXXX]]- \\
\hline 7 & [ [no- eso es su- usted tiene que probar & 7 & ¡se lo pruebo! \\
\hline 8 & eso/]] & 8 & [[se lo pruebo \| está en videos \| \\
\hline 9 & [ [usted tiene que probarlo $\mid y$ ante las & 9 & computador/ | pero si les cerraron \\
\hline 10 & instancias judiciales $\|$ no sea & 10 & la]] investigación por presión de \\
\hline 11 & irresponsable]] & 11 & uste::des \\
\hline 12 & & 12 & {$[[(\mathrm{f})$ computador de Julián } \\
\hline 13 & ¡Por favor! | presiones | [[-:entonces & 13 & Colorado | están todos los videos $\mid$ \\
\hline 14 & resulta que ahora nosotros & 14 & de los miembros $\mid$ del XXXX]]| en \\
\hline 15 & controlamos la Fiscalía/:)]] & 15 & campamentos con menores \\
\hline 16 & si hay una investigación/ deje que se & 16 & no-no es que no hay una \\
\hline 17 & desarrolle/ & 17 & investigación/ ya la cerraron \\
\hline
\end{tabular}




\begin{tabular}{|c|l|c|l|}
\hline 18 & ¡Ah, bueno! & 18 & Entonces esas son las organizaciones \\
\hline 19 & {$[[$ a ustedes/ les sirve la Fiscalía para } & 19 & {$[$ [campesinas / | PPobres campesinos } \\
\hline 20 & unas cosas para otras no $\backslash]]$ & 20 & sometidos! $]$ | a organizaciones \\
\hline 21 & & 21 & instrumentalizadas/ | por las FARC $\mid$ \\
\hline 22 & & 22 & por el ELN y por el EPL $\mid$ \\
\hline 23 & & 23 & ipobrecitos! \\
\hline
\end{tabular}

38:05-38:54

La diputada sostiene que los campesinos son víctimas de las organizaciones no gubernamentales (ONG) controladas o infiltradas por las guerrillas, mientras que el diputado la acusa de criminalizar a esas ONG y, por extensión, al campesinado que las conforma o protege. Al asumirse como portavoces, los diputados suben el tono de la discusión en nombre de la indignación y la solidaridad con ese sector vulnerable; se juega aquí la legitimidad de representación, tanto de ellos mismos y de sus partidos como de las organizaciones campesinas que, en el discurso de la diputada, quedan bajo sospecha de encubrir a las guerrillas. Los golpes y contragolpes se alternan debajo de los solapamientos en la interacción; al desagregarlos, se obtienen los siguientes pares de acción-reacción:

(1) petición de respeto $\leftrightarrow$ rechazo; $\rightarrow$ (2) exigencia probatoria $\leftrightarrow$ apariencia probatoria; $\rightarrow$ (3) burla $\leftrightarrow$ reclamo; $\rightarrow$ (4) reclamo $\leftrightarrow \mathrm{impu-}$ tación solidaria.

La dinámica erística pone en tensión las fuerzas de cada actividad de habla y las encadena en el orden de la lucha; las flechas dobles permiten ver las relaciones de fuerza; y las flechas de continuidad, los encadenamientos entre interacciones tensionadas. En (1) el rechazo de la petición se basa en la presentación de los campesinos como guerrilleros que "reclutan niños", afirmación en que la diputada hace mayor énfasis. La transición hacia (2) es, entonces, una reacción a ese énfasis, a través de la cual el diputado exige responsabilizarse de las imputaciones con evidencia probatoria. El paso hacia (3) se enfoca en el reforzamiento de la imputación y el simulacro de las pruebas, en el tramo en que la diputada sube más la voz e insiste en el énfasis puesto en el reclutamiento de menores. La reacción del diputado 
introduce la burla descalificadora frente a la acusación de bloquear el proceso judicial que permitiría demostrar su denuncia. Así, la transición de (3) a (4) es un intercambio de reclamos que pasan de la defensa al ataque en la voz de ambos contendientes: cada uno denuncia que el enemigo usa el aparato judicial para sus propios intereses. La interacción se cierra parcialmente con la búsqueda de representación política de los campesinos como víctimas por parte de la diputada; su última exclamación (“ipobrecitos!”) es, por el momento, la prueba de haber ganado la lucha a través de una imputación en nombre de su solidaridad con las víctimas.

La criminalización de las organizaciones campesinas se basa en la premisa de que las FARC las ha cooptado para escudarse en su legalidad y delinquir impunemente. Ante la dificultad de probar esa acusación, la diputada utiliza como arma el tema aberrante del reclutamiento de menores como parte de esos delitos ocultados; imputación que el diputado no intenta negar, pero sí rechazar. La disputa se enardece alrededor de ese problema aún no resuelto en el acuerdo de paz, pues las FARC han buscado justificaciones para presentar esa práctica como excepcionalidades o daños colaterales de la guerra (Olave, 2017, pp. 613-614), mientras que la sociedad civil ha encontrado en ella uno de los principales obstáculos para aceptar la reinserción de las FARC y el propio acuerdo de paz. En efecto, como se ha diagnosticado en los estudios del conflicto armado colombiano, los delitos que comprometen la integridad física y moral de los niños son percibidos como los más infames (Centro Nacional de Memoria Histórica [CNMH], 2013, pp. 84-87; Springer, 2012, p. 8); las confrontaciones por la implementación del acuerdo de paz encuentran en este tipo de temas una táctica para exhortar al castigo innegociable de los victimarios y para bloquear las políticas de amnistía y reconciliación después del conflicto.

La base de esos puntos más frágiles del acuerdo, y por tanto de su implementación en Colombia, es la apelación a principios morales innegociables. Esos principios actúan como medios de distanciamiento que utilizan los contendientes para mantener o profundizar la distancia entre sí, por un lado, y para sectorizar los grupos sociales a favor y en contra de la moral que defienden, por otro. En la moral reclamada, en este sentido, se generan las 
actitudes y los juicios que separan a los interlocutores en dos bandos opuestos desde los cuales se atacan y se defienden. El caso del reclutamiento de menores, entre otros, constituye la violación de un principio moral que, en la voz de la oposición, traduce el acuerdo de paz en impunidad y su implementación en revictimización de los más vulnerables.

\section{Conclusión}

En este artículo, se propuso el análisis de un conjunto de intercambios verbales entre dos políticos colombianos en un programa radial de debates con retransmisión en vivo. El foco del estudio fue la disputa agresiva entre los participantes en torno a la implementación del acuerdo de paz firmado entre el Estado colombiano y las FARC en 2016. Los ejemplos ofrecidos en los resultados no agotan el análisis de la disputa por la representación de los colectivos, sino que destacan algunas tácticas de combate desplegadas alrededor de la legitimidad del acuerdo, como objeto de discordia, y de la idea política de representación democrática como campo de batalla. En este terreno, se mostró que la aceptación y el rechazo de las premisas sobre la legitimidad/ilegitimidad del acuerdo de paz determinó las formas del ataque y la defensa entre los diputados en pugna.

Con la firma del tratado de paz entre el Estado colombiano y las FARC en 2016 , los partidos políticos y los sectores sociales representados radicalizaron sus posiciones favorables y desfavorables. Después de esa firma y de las dificultades que encontró el Gobierno para llevar a cabo una refrendación popular del acuerdo, la oposición supo hacer escuchar sus demandas y bloquear la implementación de lo acordado.

Las discordias entre esos sectores han sido llevadas al escenario de los debates públicos mediatizados. El periodismo de opinión ha explotado las posibilidades recientes de transmisión en vivo para las redes sociales virtuales, reciclando géneros radiales tradicionales como el debate y adaptándolos a las particularidades de estas nuevas audiencias; en especial, al interés por la transmisión de imágenes y opinión de la audiencia en tiempo real. En este texto, se propuso el análisis de un debate retransmitido bajo esas condiciones, entre dos diputados pertenecientes a colectividades políticas y 
sociales en abierta oposición, a propósito de la pregunta por la implementación del acuerdo de paz con o sin modificaciones.

La aproximación a esta disputa no se interesó por determinar — por fuera de lo que aseguren los contendientes - cuál es el mejor argumento, quién tiene la razón, cómo coexistir en la diferencia o cómo se pueden vehiculizar consensos. Esos esfuerzos evaluativos e inclusive prescriptivos sobre las disputas públicas y la argumentación misma, si bien interesantes, no agotan la comprensión de las disputas públicas como interacciones con múltiples tramos en los cuales las reglas del debate ceden a los imperativos del combate. Las características espaciotemporales del escenario del combate (mediatización, participación y retransmisión en vivo), así como las especificidades del evento y de sus contendientes, condicionan el desarrollo de la lucha, el uso de los arsenales y el despliegue de las acciones verbales.

El análisis del caso de los parlamentarios en confrontación permitió abordar un tipo de disputa caracterizado por las exigencias de la interacción cara a cara, en la cual las demostraciones de fuerza tienen un alto grado de improvisación y de urgencia. Las limitaciones para la planeación de ataques y defensas verbales conducen a intercambios ágiles, reacciones vehementes y movidas predominantemente intuitivas en los tramos de mayor tensión.

En esta disputa de los parlamentarios sobre la implementación del acuerdo de paz, los arsenales verbales y paraverbales movilizados en las tácticas hicieron que la lucha fuera dominada por una agresividad discreta: una forma de ataque indirecto que atrinchera la agresión detrás de la discreción, evitando transgredir fórmulas corteses, lo que permite el despliegue de la fuerza y la reducción del riesgo de ser señalado públicamente como el sujeto violento. Esta forma de agresión se transparenta en la recurrencia de diferentes recursos verbales, paraverbales y no verbales, que aparecen utilizados en las movidas de ataque, defensa y clinch (o bloqueo mutuo en tensión); las principales son la conservación de las fórmulas corteses de tratamiento, el encadenamiento de negaciones, la entonación aseverativa a través de 
tonemas descendentes, los énfasis prosódicos en lexemas clave de contestación enérgica, el control del volumen de la voz, preferiblemente bajo, y los usos políticos de la risa/sonrisa.

La agresividad discreta es un signo de la ampliación de la "corrección política” en la conformación normativa del espacio público, desde sus instituciones reguladoras y bajo la pretensión de realizar cambios sociales a partir de cambios en las prácticas discursivas (Fairclough, 2009, pp. 502505). Esa extensión ya no solo señala como inadecuado o mal visto el uso no incluyente de la lengua, sino también su uso directo, despojado de eufemismos y con intenciones agresoras. En sus intervenciones públicas y particularmente en situaciones de debate, los representantes políticos se ven obligados a preservar esa corrección como parte fundamental de su imagen favorable, formalidad que garantizaría su "dignidad" como políticos, pero al mismo tiempo el componente erístico de los debates exige el ataque para someter a los contradictores.

Las fuerzas políticas contrapuestas, en el momento histórico de la transición hacia la paz con las guerrillas colombianas, luchan a favor y en contra de la implementación del tratado firmado. Para el sector de oposición, se trata de "desacordar el acuerdo" desde el reclamo de haberlo derrotado con la victoria del No en el plebiscito refrendatorio. Ese reclamo del trofeo no concedido bloquea la implementación de lo acordado y arroja a la lucha a los contradictores.

Es un combate que se gana o se pierde en la arena del logos público, donde la victoria depende de la aprobación popular y la aceptación de la victoria defendida por cada contendiente. El logos político se convierte en logos de la victoria cuando se logra convencer a la tribuna del sometimiento del enemigo a través del poder de la palabra en el combate verbal, no solo como "victoria de una opinión en una asamblea o [como] ventaja que obtiene una facción sobre otra al salir de una stasis" (Loraux, 1997, p. 67), sino también en el sentido de la naturaleza inevitablemente grave y atroz de la victoria a través de la fuerza, cuya única garantía de reconocimiento público es la exhibición de su dureza, sin contemplaciones. Ese sometimiento, trabajo del logos, es la victoria. 
Finalmente, este recorrido analítico no pretende agotar la riqueza de la disputa seleccionada, sino que destaca la centralidad de los combates verbales mediatizados por la radio de opinión en streaming y el estrecho marco del esquema de la victoria y la derrota (¿quién ganó/quién perdió?) en las discusiones públicas. Se ha defendido aquí que esta realidad deliberativa y el tipo de discusión política que circula en los medios actualmente, más allá de la sanción que nos merezca, requiere un estudio dedicado que permita comprender mejor nuestra democracia al reflejarla en el espejo negro de sus combates verbales.

\section{Referencias}

Amossy, R. (2014). Apologie de la polémique. París, Francia: PUF.

Amossy, R. (2017). Por uma análise discursiva e argumentativa da polêmica. EID \& A, 13, 227-244.

Angenot, M. (1994). Les Idéologies du ressentiment. Montreal, Canadá: Université McGill.

Angenot, M. (2008). Dialogue du Sourds. París, Francia: Mille et Une Nuits.

Angenot, M. (2013). Rhétorique de la confiance et de l'autorité. Montreal, Canadá: Université McGill.

Aristóteles. (1991). Sobre las refutaciones sofísticas. Madrid: Gredos.

Arnoux, E. (2006). Análisis del discurso. Buenos Aires, Argentina: Santiago Arcos.

BBC Mundo. (2016, septiembre 14). Humberto de la Calle: el primer paso es que los colombianos entiendan que "no hay violencia buena". Recuperado de https://www.bbc.com/mundo/noticias-america-latina-37357984 
Cebrián Herreros, M. (2001). La radio en la convergencia multimedia. Madrid, España: Gedisa.

Centro Nacional de Memoria Histórica (2013) ¡Basta ya! Colombia: memorias de guerra y dignidad. Bogotá, Colombia: Grupo de Memoria Histórica. Recuperado de http://www.centrodememoriahistorica.gov.co/descargas/informes2013/bastaYa/basta-ya-memoriasguerra-dignidad-new-9-agosto.pdf

Danblon, E. (2005). La fonction persuasive. París, Francia: Armand Colin.

Fairclough, N. (2009). 'Políticamente correcto': la política de la lengua y la cultura. Discurso \& Sociedad, 3(3), 495-512. Recuperado de http:// www.dissoc.org/ediciones/v03n03/DS3\%283\%29Fairclough.html

Ferrero, G. (1998). Poder: los genios invisibles de la ciudad. Madrid, España: Tecnos.

Fracchiolla, B. (2008). L'attaque courtoise. Ponencia presentada en JADT 2008: 9es Journées internationales d'Analyse statistique des Données Textuelles.

Gauthier, G. (2012). Le cadre éristique du débat argumentatif. Communication, 30(2). Recuperado de https://journals.openedition.org/ communication $/ 3570$

Goldberg, J. (2010). Interrupting the discourse on interruptions: An analysis in terms of relationally neutral, power- and rapport-oriented acts. Journal of Pragmatics, 14(6), 883-903. DOI: 10.1016/03782166(90)90045-F

Habermas,J. (1989). Teoría de la acción comunicativa. Madrid, España: Taurus.

Jackiewicz, A. (2017). Outils notionnels pour l'analyse des controverses. Questions de Communication, 31, 137-159. Recuperado de https:// 
www.cairn.info/revue-questions-de-communication-2017-1-page-137.htm

Jenks, C. J. (2011). Transcribing talk and interaction: Issues in the representation of communication data. Ámsterdam, Países Bajos: John Benjamins Publishing.

Kerbrat-Orecchioni, C. (2007). Lanalyse du discours en interaction: quelques principes méthodologiques. Limbaje si comunicare, 9, 13-32.

Kerbrat-Orecchioni, C. (2010). Pour une analyse multimodale des interactions orales. Cadernos de Letras da UFF-Dossiê: Letras, linguística e suas interfaces, 40, 17-45. Recuperado de http://www.cadernosdeletras.uff.br/joomla/images/stories/edicoes/40/artigo1.pdf

Kerbrat-Orecchioni, C. (2016). Le désaccord, réaction «non préférée»? Cahiers de Praxématique, 67. Recuperado de http://journals.openedition.org/praxematique/4524

Kock, C. (2007). Norms of legitimate dissensus. Informal Logic, 27(2), 79196. DOI: $10.22329 /$ il.v27i2.474

Kock, C. (2009). Constructive controversy: Rhetoric as dissensus-oriented discourse. Cogency, 1(1), 89-111. Recuperado de https://mcc. $\mathrm{ku} . \mathrm{dk} / \mathrm{staff} / \mathrm{rhetoric} /$ ?pure $=\mathrm{en} \% 2 \mathrm{Fpublications} \% 2 \mathrm{Fconstructi}$ ve-controversy(64713ff0-b1a4-11de-bc73-000ea68e967b).html

Kotarbinski, T. (1963). L'éristic, cas particulier de la théorie de la lutte. Logique et Analyse, 6, 19-29.

Laclau, E. y Mouffe, C. (1987). Hegemonía y estrategia socialista. Buenos Aires, Argentina: Fondo de Cultura Económica.

Liddicoat, A. (2007). An introduction to conversation analysis. Londres, RU: Continuum.

Loraux, N. (1997). La ciudad dividida. Buenos Aires, Argentina: Katz. 
Maingueneau, D. (1983). Semantique de la polémique. París, Francia: L’Age d'Homme.

Marchart, O. (2007). Politics and the political: Genealogy of a conceptual difference. En Post-foundational political thought: Political difference in Nancy, Lefort, Badiou and Laclau (pp.35-60). Edimburgo, Escocia: Edinburgh University Press.

Montero, A. S. (2016). La polémica y lo polémico: palabras preliminares. En A. S. Montero (Coord.), Análisis del discurso polémico (pp. 9-22). Buenos Aires, Argentina: Prometeo.

Mouffe, C. (2000). La paradoja democrática. Barcelona, España: Gedisa.

Nussbaum, M. (2013). Political emotions. Cambridge, RU: The Belknap Press.

Olave, G. (2017). Construcciones retóricas de la oposición política en el conflicto armado colombiano: los discursos de la guerrilla FARC-EP y del presidente Juan Manuel Santos (Tesis de doctorado, Universidad de Buenos Aires, Buenos Aires, Argentina).

Olave, G. (2018). Para una retórica del desacuerdo en contextos violentos. Manuscrito no publicado, Agencia Mexicana de Cooperación Internacional para el Desarrollo, México.

Pulido Esteban, F. y Sánchez Calero, M. L. (2017). Facebook Live: un nuevo canal para la entrevista. En J. A. González-Alba (Coord.), Tendencias e innovación en la empresa periodística (pp. 85-102). Sevilla, España: Egregius.

Plantin, C. (2003). Des polémistes aux polémiqueurs. En G. Declercq, M. Murat y J. Dangel (Eds.), La parole polémique (pp. 377-408). París, Francia: Champion.

Plantin, C. (2011). "No se trata de convencer, sino de convivir". Lère pospersuasion. Rétor, 1(1), 59-83. 
Plantin, C. (2012). La normalidad del desacuerdo. Praxis Filosófica, 35, 283-301. Recuperado de http://www.scielo.org.co/scielo. php?script $=$ sci_arttext\&pid=S0120-46882012000200013

Quiroga, H. (2013). Repensar la legitimidad democrática. En I. Cheresky (Comp.), ¿Qué democracia en América Latina? (pp. 55-82). Buenos Aires, Argentina: Consejo Latinoamericano de Ciencias Sociales.

Red Nacional de Información. (2017, diciembre 1). Registro Único de Victimas. Recuperado de https://www.unidadvictimas.gov.co/es/registro-unico-de-victimas-ruv/37394

Registraduría Nacional del Estado Civil. (2016). Plebiscito 2 de octubre de 2016. Recuperado de https://elecciones.registraduria.gov.co/ pre_plebis_2016/99PL/DPLZZZZZZZZZZZZZZZZZ_L1.htm

Reygadas, P. (2015). El arte de argumentar. Ciudad de México, México: Universidad Autónoma de la Ciudad de México.

Rosanvallon, P. (2002). Por una historia conceptual de lo político. Buenos Aires, Argentina: Fondo de Cultura Económica.

Rosanvallon, P. (2007). La contrademocracia. Buenos Aires, Argentina: Manantial.

Rosanvallon, P. (2009). La legitimidad democrática. Buenos Aires, Argentina: Manantial.

Ruusuvuori, J. (2013). Emotion, affect and conversation. En J. Sidnell y T. Stivers (Eds.), The handbook of conversation analysis (pp.330-349). Oxford, RU: Wiley-Blackwell Publishing.

Sandré, M. (2011). Mimiques et politique: analyse des rires et sourires dans le débat télévisé. Mots, les langages du politique, 96. DOI: 10.4000/ mots. 20203 
Santos, J. M. (2016, junio 16). Asegurar la paz en Colombia. Medellín, Colombia: Foro Económico Mundial.

Semana. (2016, agosto 20). Qué pasa si gana el NO. Recuperado de https:// www.semana.com/nacion/articulo/que-pasa-si-gana-el-no/489580

Schopenhauer, A. (1830/2011). Dialéctica erística. Madrid, España: Trotta.

Soengas Pérez, X. (2013). Retos de la radio en los escenarios de la convergencia digital. adComunica, 5, 23-36. DOI: 10.6035/21740992.2013.5.3

Springer, N. (2012). Como corderos entre lobos: del uso y reclutamiento de niñas, niños y adolescentes en el marco del conflicto armado y la criminalidaden Colombia. Bogotá, Colombia: Springer Consulting Services.

Uribe Vélez, Á. (2016, agosto 3). Nuestra campaña por el No. Recuperado de https://www.centrodemocratico.com/?q=articulo/nuestracampana-por-el-no-uribe

Weber, M. (1922/1979). Economía y sociedad (2.a ed.). Ciudad de México, México: Fondo de Cultura Económica.

W Radio (2017, septiembre 22). María Fernanda Cabal e Iván Cepeda en el cuadrilátero de La W. Recuperado de http:/ /www.wradio.com. co/noticias/actualidad/maria-fernanda-cabal-e-ivan-cepeda-enel-cuadrilatero-de-la-w/20170622/nota/3500330.aspx

Zarka, Y. (2010). La legitimité démocratique en question. En Y. Zarka (Coord.), Repenser la démocratie. París, Francia: Armand Colin. 


\section{Anexo}

\section{Convenciones de la transcripción}

DIPo $\rightarrow \operatorname{Diputado}(p) \rightarrow$ voz baja (piano)

DIPa $\rightarrow$ Diputada (???) $\rightarrow$ ininteligible

MOD $\rightarrow$ Moderador $(f) \rightarrow$ voz alta (forte)

$[[\mathbf{a b c}]] \rightarrow$ Solapamientos MAY $\rightarrow$ cercano al grito

- $\rightarrow$ interrupción abrupta $\underline{\mathrm{abc}} \rightarrow$ énfasis

$\| \rightarrow$ micropausa ( 1 segundo) $\rightarrow \rightarrow$ alargamiento simple

$\mid \rightarrow$ micropausa (menos de 1 segundo) $:: \rightarrow$ alargamiento múltiple

(:) $\rightarrow$ risa/sonrisa/ $\rightarrow$ tonema ascendente

(-)abc): $\rightarrow$ voz sonriente $\backslash \rightarrow$ tonema descendente

"abc" $\rightarrow$ cita XXX $\rightarrow$ protección de nombre propio

¿abc? $\rightarrow$ pregunta $\ldots \rightarrow$ omisión de inicio

$¡ a b c$ ! exclamación $[. ..] \rightarrow$ recorte del analista 